\title{
A High-Density Heat-Sink-Mounted Inductor for Automotive Applications
}

\author{
Mark Gerber, Jan Abraham Ferreira, Senior Member, IEEE, Ivan W. Hofsajer, Member, IEEE, and Norbert Seliger
}

\begin{abstract}
Passive components, and inductors, in particular, contribute greatly to the overall volume of power electronic converters. These components are normally packaged individually with little concern for the overall system. For high-density switching power supplies it is imperative to minimize the volume to as great an extent as possible which implies that the passive component volume usage needs to be improved. This can be accomplished by applying suitable packaging and cooling techniques to these components. In this paper, two inductor structures finding application in a $2.1-\mathrm{kW}$ synchronous automotive converter are described. The air-gap placement, losses, cooling methods, and thermal profiles are analyzed and verified experimentally with an inductor designed for operation at $85^{\circ} \mathrm{C}$ ambient.
\end{abstract}

Index Terms-Direct heat removal, high power density, high temperature, indirect heat removal, packaging, passive component.

\section{INTRODUCTION}

$\mathbf{P}$ ASSIVE components are a necessary part of any power electronic system. They are often the components that limit the volume reduction of the system (and, thus, the power density) as well as contribute significantly to the system losses [1]. The temperature limitations of the materials and the losses generated within them determine the dimensions of the component. For example, it may be possible to build a highly efficient inductor, but in order to achieve this, the materials constituting the inductor are not excited to near their maximum points of operation, significantly reducing the inductor losses. This results in an inductor structure that operates with low internal temperatures but has a significant volume. On the other hand, if the inductor volume is to be reduced, the utilization of the materials needs to be maximized. Consequently, there are more losses generated in the smaller volume resulting in an increased loss density and higher material temperatures. For the inductor to operate successfully, the generated heat must be removed more effectively.

Paper IPCSD-04-021, presented at the 2002 Industry Applications Society Annual Meeting, Pittsburgh, PA, October 13-18, and approved for publication in the IEEE TRANSACTIONS ON IndUSTRY APPLICATIONS by the Power Electronics Devices and Components Committee of the IEEE Industry Applications Society. Manuscript submitted for review January 1, 2003 and released for publication April 2, 2004.

M. Gerber and J. A. Ferreira are with the Faculty of Electrical Engineering, Mathematics and Computer Science, EWI Faculty, Delft Technical University, 2600GA Delft, The Netherlands (e-mail: M.Gerber@EWI.TUDelft.nl; J.A.Ferreira@EWI.TUDelft.nl

I. W. Hofsajer is with the Industrial Electronics Technology Research Group, Rand Afrikaans University, Johannesburg 2006, South Africa (e-mail iwh@ieee.org).

N. Seliger is with Corporate Technology, Siemens AG, D-81730 Munich, Germany (e-mail: Norbert.Seliger@mchp.siemens.de).

Digital Object Identifier 10.1109/TIA.2004.830766
Thus, the thermal characteristics of the inductor begin to play a more pronounced role in the design as the loss density increases.

A number of high-power-density inductor and transformer design procedures have been documented in the literature [2]-[4]. These designs have all been for use in converters with power levels larger than $0.5 \mathrm{~kW}$. It is generally accepted that the design of passive components is thermally limited, and as such the documented designs include some form of thermal modeling as part of the design process. The thermal models are generally based on a lumped parameter equivalent circuit which is easy to apply. The lumped parameters of the model can, however, be difficult to determine, and several empirical equations are normally employed. [5] The magnetic structures are also generally designed to be used in free air, further complicating the determination of the parameters. The possibility of magnetic structures cooled by other means is mentioned in [6], where heat pipes are introduced for planar magnetics. This is, however, not discussed at length.

The thermal advantages of planar magnetics is recognized [4], [6] in addition to that of low profile. With planar magnetics the larger cooling surface implies lower thermal resistance. They can, therefore, run at higher loss densities for a given temperature rise [3].

In this paper, a planar inductor structure for use in a highpower-density switching converter is introduced and analyzed. The inductor structure is totally enclosed in a heat sink, which leads to a very well defined and predictable temperature distribution. The magnetic implications of the heat sink in close proximity to the windings and air gaps are evaluated and the necessity to pay equal attention to both the thermal as well as magnetic designs is emphasised.

The theoretical losses in the structure are determined by means of finite-element analysis for various planar core geometries. The theoretical temperature profile is also determined by means of finite-element analysis using the previously determined loss data. The investigated structures are then experimentally evaluated.

\section{A. Converter Topology}

The investigated inductor structures find application in a bidirectional dc/dc converter of a dual-voltage system (14/42 V) for automotive application [7]. The specific dc/dc converter topology under consideration is shown in Fig. 1. The topology consists of three bidirectional, synchronous rectified, time interleaved phase arms with common input and output bus capacitors. Only one phase with the common input and output capacitors is shown in Fig. 1. The topology is reported on in the 


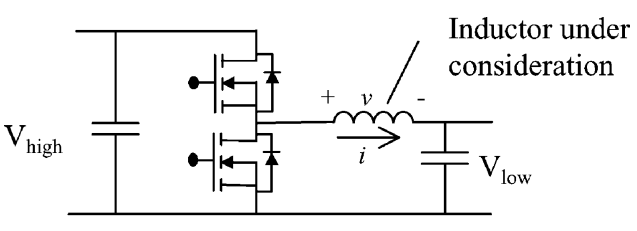

(a)

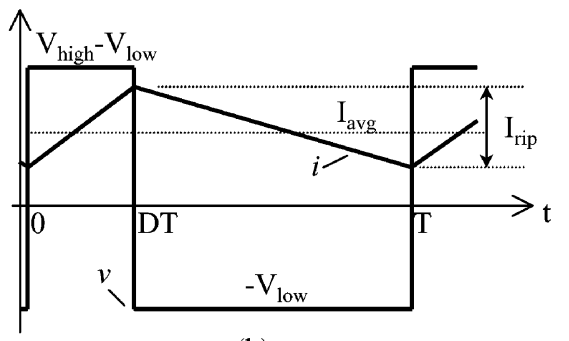

(b)

Fig. 1. (a) The dc/dc converter topology and (b) typical excitation.

TABLE I

INDUCTOR REQUIREMENTS AND CHARACTERISTICS

\begin{tabular}{c|c}
\hline Property & Value \\
\hline Inductance & $2.2 \mu \mathrm{H}$ \\
\hline Average Current & $50 \mathrm{~A}$ \\
\hline Ripple Current & $25 \mathrm{~A}( \pm 12.5 \mathrm{~A})$ \\
\hline Operating Frequency & $170 \mathrm{kHz}$ \\
\hline Number of turns & 2 \\
\hline Max flux density & $245 \mathrm{mT}_{\text {peak }}$ \\
\hline $\begin{array}{c}\text { Max AC flux density } \\
\text { excursion }\end{array}$ & $100 \mathrm{mT}_{\mathrm{p}-\mathrm{p}}$ \\
\hline Magnetic cross section & $280 \mathrm{~mm}^{2}$ \\
\hline Footprint & $\begin{array}{c}\text { Width }=30 \mathrm{~mm} \\
\text { Depth }=50 \mathrm{~mm}\end{array}$ \\
\hline Height & $10 \mathrm{~mm}$ \\
\hline
\end{tabular}

literature [7] and only the inductor is of further interest. The total power of the converter is $2.1 \mathrm{~kW}$ giving a power of 700 $\mathrm{W}$ per phase arm.

The converter is to operate in an automobile engine compartment where space is at a premium. The power density of the converter is, therefore, of prime importance. The cooling of the converter is specified to be via a closed loop water system with a nominal temperature of $85^{\circ} \mathrm{C}$. The converter structure is totally encapsulated and mounted flat on the water cooled base [8]. The thermal contribution from the ambient air surrounding the structure is ignored due to the very much smaller thermal impedance to the water cooled base. All the heat generated in the converter and in particular the inductor structure must therefore be conducted to an infinite heat sink with an ambient temperature of $85^{\circ} \mathrm{C}$.

\section{B. Inductor Description}

The operational requirements and properties of the inductor are shown in Table I. The voltage and current waveforms of the inductor under steady-state maximum power transfer conditions are shown in Fig. 1. Due to the footprint constraints, as well as the high current requirement, the inductor is implemented with a two-turn winding. A planar structure was chosen as the base to work from due to the structures increased surface area allowing for better heat transfer. A two-turn structure also allows

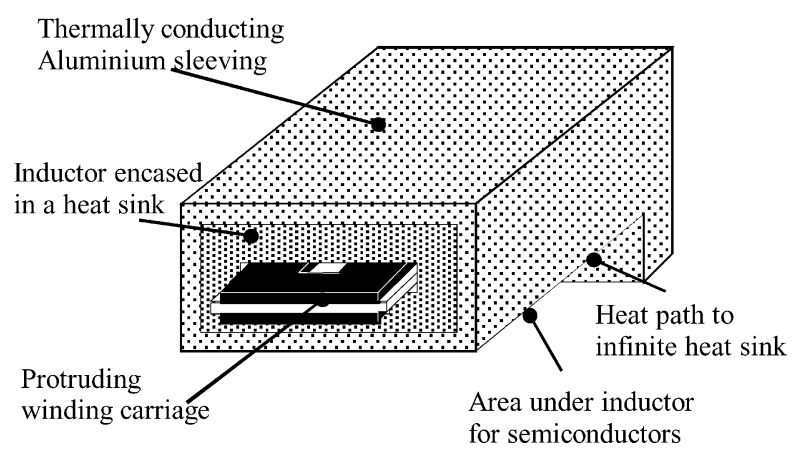

Fig. 2. Two-turn planar inductor encased in an aluminum heat sink.

easier access to the alternate surface of the copper conductors improving the thermal management.

The heat generated in the inductor structure is removed only by thermal conduction, an assumption justified by the operating environment. To facilitate the heat conduction from the inductor structure to the infinite heat sink, the entire planar inductor structure is encased in an aluminum sleeving as illustrated in Fig. 2. Only the inductor winding connections protrude from the front of the inductor structure. The heat sink at the back of the sealed inductor structure is extended down to the infinite heat sink. This extension forms a heat path between the inductor and the infinite heat sink conducting all the generated heat away from the inductor. It is assumed that this heat path is the only way for the heat to be removed from the inductor and transported to the heat sink. The inductor structure can not be mounted directly on the infinite heat sink as the space directly below it is reserved for semiconductor devices [8].

The inductor core is implemented with a high flux density ferrite (Philips 3F3) chosen for low loss at the operating frequency. The two-turn winding is implemented with a 1-mm-thick copper plate supported by an FR4 winding carriage.

There will be magnetic flux leakage out of the core, especially at the air gaps, into the aluminum sleeving. The magnetic flux leakage will interact with the sleeving, causing additional losses in the sleeving due to eddy currents. In order to determine the validity of the proposed heat removal method, the interaction between the inductor structure and sleeving is investigated.

Under conditions of thermal cycling the structure will experience thermal stress. This is especially a problem between the ferrite and the aluminum heat sink, due to different coefficients of thermal expansion $\left(11 \times 10^{-6}{ }^{\circ} \mathrm{C}^{-1}\right.$ and $24 \times 10^{-6}{ }^{\circ} \mathrm{C}^{-1}$, respectively). In order to alleviate this problem the heat sink is sized to be just larger than the inductor. The space between the two materials is filled with a thermally conducting electrically isolating material (Chromerics F574). This material is typically very malleable and compressible. As the temperature increases and the two materials begin to expand, the thermal material is compressed between the material surfaces. In this way, the heat sink and the ferrite have a degree of freedom as the materials expand. The thickness of the thermally conductive material is chosen so that under full excitation, both electrical and thermal, the heat sink and the ferrite materials do not touch directly. The same thermally conductive material is used between the copper conductors and the ferrite, and is again used to prevent induced thermal stresses while providing a good heat path. 


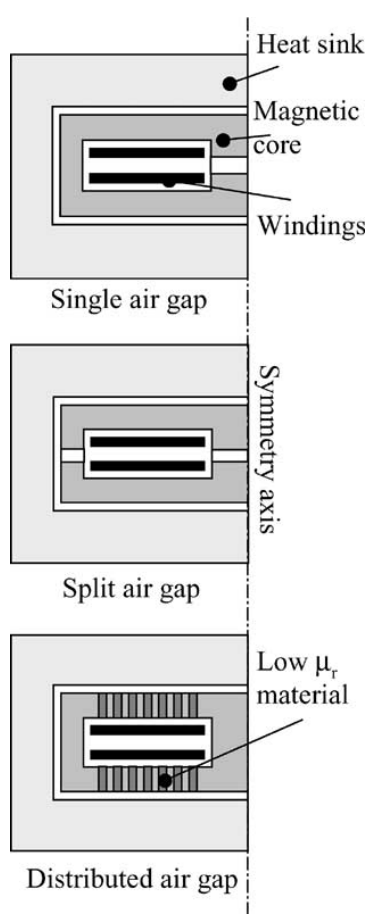

Fig. 3. Three different energy storage gap configurations investigated.

\section{LOSS ANALYSIS}

\section{A. Conduction Loss in Winding Window}

The losses in the winding window are primarily due to the presence of an air gap that causes magnetic flux fringing and localized induced eddy currents. The position and nature of the energy storage gap in the winding window cross section influences the magnitude of these losses [9], [12]. Three different configurations of the energy storage gap were considered. The three different structures are shown in cross section in Fig. 3, perpendicular to the direction of current flow:

1) a single lumped air gap in the center member of the ferrite core;

2) a split air gap; the air gap is implemented in both the center and outer members of the ferrite core;

3) a distributed gap; the distributed gap is implemented in the upper and lower ferrite members of the structure.

A possible further implementation has a distributed air gap in the center leg. This case was not considered due to the difficulty in implementing a distributed air gap in this leg as the planar core has a very short center leg.

To evaluate the interaction of the energy storage volume and the heat sink on the structure losses, the three different air-gap configurations of the inductor structure are considered in two-dimensional finite-element simulations. The finite-element method (FEM) simulation performed is a high-frequency ac analysis [10]. Both the skin and proximity effects play a role in the current distribution in the structure and are taken into account automatically by the simulation.

All the simulations are evaluated under full excitation as defined in Table I. The inductor current, as shown in Fig. 1, is reduced to its Fourier components and each component used in
TABLE II

Material CONDUCTIVITIES USED IN THE AC ANALYSIS

\begin{tabular}{c|c}
\hline Material & Conductivity $\left[{\left.\mathrm{S} . \mathrm{m}^{-1}\right]}^{-1}\right.$ \\
\hline Copper conductors & $58 \times 10^{6}$ \\
\hline Ferrite & 0.5 \\
\hline Aluminium heat sink & $38 \times 10^{6}$ \\
\hline
\end{tabular}

TABLE III

DISTRIBUTED GAP PROPERTIES

\begin{tabular}{c|c}
\hline Property & Value \\
\hline $\begin{array}{c}\text { Relative permeability of core } \\
\text { material (3F3) }\end{array}$ & 2000 \\
\hline $\begin{array}{c}\text { Relative permeability of gap } \\
\text { material (C351) }\end{array}$ & 9 \\
\hline Number of gaps & 14 \\
\hline Gap width & $0.4 \mathrm{~mm}$ \\
\hline Gap pitch & $1.1 \mathrm{~mm}$ \\
\hline $\begin{array}{c}\text { Effective relative permeability } \\
\text { of gap }\end{array}$ & 25 \\
\hline Effective length of gap & $15.4 \mathrm{~mm}$ \\
\hline
\end{tabular}

a separate simulation. The first four harmonics as well as the average (dc) current is used.

The magnetic flux distribution and the resulting eddy currents within the structure for the different geometries at specific frequencies were determined. From the current distribution the resistance and hence the losses in the structure can be determined. Summing the losses at each harmonic then approximates the total conduction loss.

The conductivities of the materials used for the simulation are given in Table II.

For the case of the single air gap, the gap in the center leg of the core is $0.62 \mathrm{~mm}$ thick and has a relative permeability of unity. In a similar fashion the split air gap in the center and outer leg of the core is $0.31 \mathrm{~mm}$ thick (Fig. 3). For both split and single air gap the relative permeability of the core material was 2000.

The distributed air gap consists of a series of small gaps separated by a high-permeability material. This quasi-distributed gap closely approximates a low-permeability material [9]. Practically, and for simulation purposes, the core is constructed from 3F3 (Philips) material with each gap filled with C351 material (EPCOS). The material and gap specifications are given in Table III. The gap pitch in the table is defined as the distance between two consecutive gaps. The distributed gaps are located in the upper and lower ferrite members as shown in Fig. 3(c). From a manufacturing point of view the distributed air gap is quite difficult. There are a large number of separate ferrite parts that each need to be fabricated and assembled. There are over 55 separate pieces in the core described here. This is a very costly manufacturing process, and not at all suited to mass production. In such a case it would be imperative to reduce the number of parts by better matching of the air gap ferrite to the required air-gap permeability. Alternatively, the number of discrete air gaps could be reduced. This optimization process has not been carried out in this work.

The simulation results of the magnetic flux density path are shown in Fig. 4. This result is for the sum of the first four harmonic currents. The dc component is not included. These results show the leakage effects in the vicinity of the air gaps. 


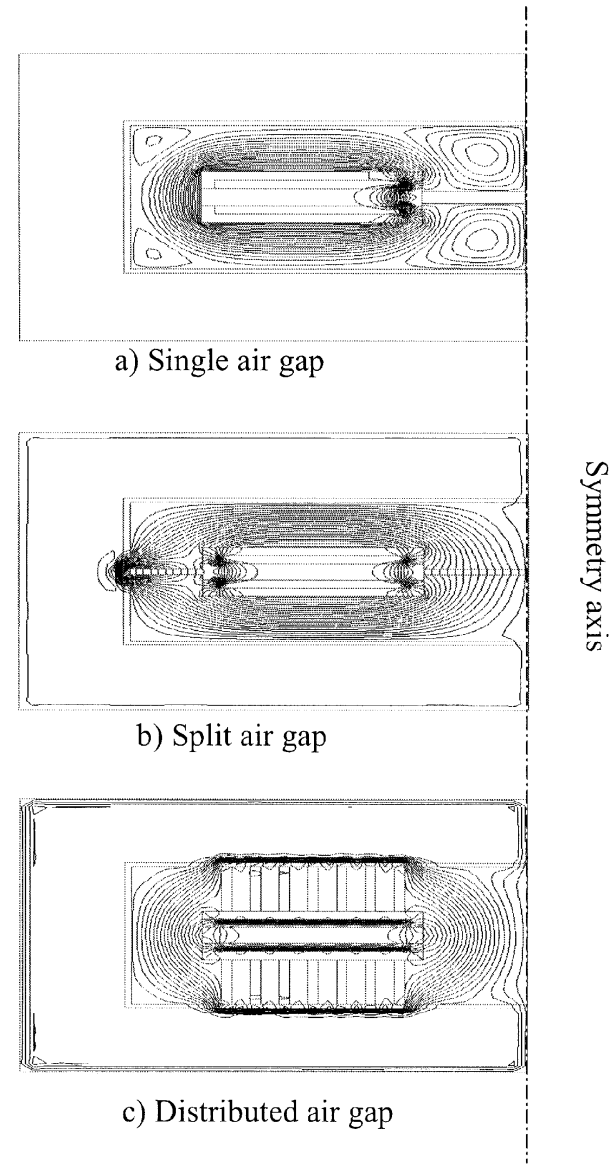

Fig. 4. Magnetic flux paths in the winding window.

Fig. 4(a) shows that there is significant magnetic flux leakage around the single air gap. The high leakage is due to the gap having a long length compared to the winding window height. The magnetic flux leakage results in a highly distorted current density distribution in the copper conductors [9]. This will increase the winding losses of the inductor significantly. However, the simulation also shows that there is no magnetic flux leakage into the heat sink. Thus, for a single lumped air gap, the leakage flux does not enter into the heat sink but instead distorts the current density distribution in the copper windings

Fig. 4(b) shows that with the split air gap there is magnetic flux leakage that interacts with both the copper conductors and the heat sink. Eddy currents are established in the heat sink as well and both heat sink and windings contribute to losses.

Fig. 4(c) shows the magnetic flux density distributed in the air gap. It can be seen that the magnetic flux in the distributed gap is divided into two parts that follow a path around the distributed gap. This occurs as follows. Eddy currents are induced in the heat sink above the distributed gap and in the copper winding below the distributed gap due to the magnetic flux leakage into these materials. The induced eddy currents will be orientated in such a way that their magnetic fluxes will oppose the initially applied magnetic flux. The two fluxes will summate. The result is that, in the distributed gap, the two magnetic fluxes oppose each other, resulting in the net magnetic flux density in the gap being reduced. Outside the gap, above and below, the induced magnetic flux and the initially applied magnetic flux will sum-
TABLE IV

EDDY-CURRENT LOSSES IN THE WINDING WINDOW FOR THE THREE STRUCTURES. (DC COMPONENT NOT INCLUDED)

\begin{tabular}{l|c|c|c}
\hline & $\begin{array}{c}\text { Conductor } \\
\text { losses } \\
{[\mathrm{W}]}\end{array}$ & $\begin{array}{c}\text { Heat sink } \\
\text { losses } \\
{[\mathrm{W}]}\end{array}$ & $\begin{array}{c}\text { Total } \\
\text { losses } \\
{[\mathrm{W}]}\end{array}$ \\
\hline Single air gap & 1.28 & 0 & 1.28 \\
\hline Split air gap & 0.66 & 0.82 & 1.48 \\
\hline Distributed air gap & 0.16 & 0.26 & 0.42 \\
\hline
\end{tabular}

mate, resulting in a magnetic flux density higher than that initially applied. Thus, the appearance is given that the induced eddy currents pull the magnetic flux around the gap. Additionally, as a consequence of this interaction between the copper conductors and the induced eddy current, a near-uniform current density is maintained over the area of the conductors. This results in a lower copper conductor loss than in the previous two cases.

The conduction losses due to the eddy currents in the three structures are compared in Table IV. The copper losses are the greatest for a single lumped air gap because, having the largest discrete gap of the three structures, the leakage flux effectively reaches further into the copper conductors. This influences the current distribution in the copper conductors.

By splitting the air gap into two smaller gaps, the copper conduction losses are reduced. The conduction losses are the smallest for the distributed gap because the leakage flux has been used to advantage to help maintain a near-uniform current distribution in the copper conductors.

The losses associated with the currents induced in the heat sink are effectively zero for the single lumped air-gap structure. This is because the leakage flux associated with the air-gap is placed in the center member of the inductor and does not interact with the heat sink. For the split air-gap structure the gap placed close to the aluminum heat sink induces eddy currents and, thus, losses in the heat sink. The induced losses in the distributed gap configuration are less than that for the split air-gap configuration due to the distribution of the eddy current in the heat sink. The eddy currents are not localized as in the split air-gap structure.

The ferrite conduction losses are almost inconsequential when compared to the conduction losses in the other materials. The ferrite conduction losses are low due to the low electrical conductivity of the ferrite material as listed in Table II.

\section{B. Conduction Loss Outside the Winding Window}

Two different configurations are considered for the return conductors outside of the winding window. These two configurations are shown in Figs. 5 and 6. The first is referred to as the indirect heat removal structure. In this structure the ferrite core is extended over the return conductors shielding them from the heat sink. The heat from the conductors in this structure is transferred to the heat sink via this ferrite material, hence, an indirect heat path.

The second structure is the direct heat removal structure. The structure derives its name from the fact that the copper conductors are directly clamped in the heat sink, allowing a direct transfer of heat between the conductors and the heat sink. The 


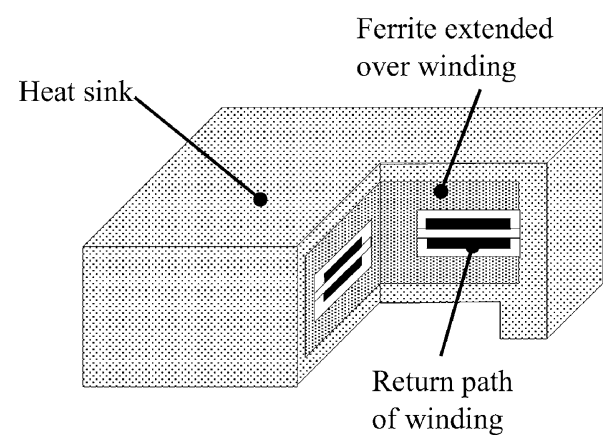

Fig. 5. Indirect heat removal structure.

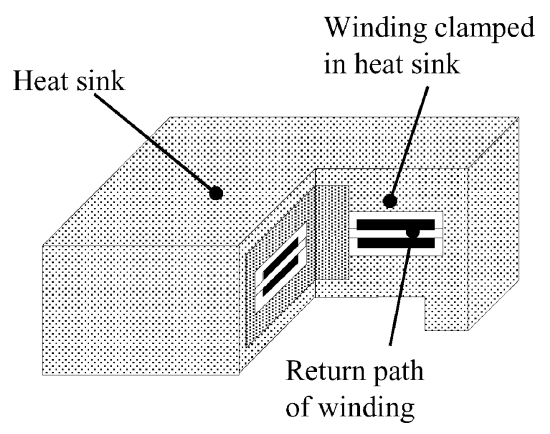

Fig. 6. Direct heat removal structure.

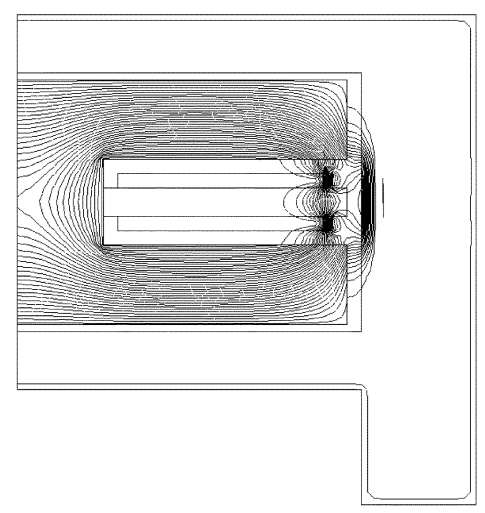

Fig. 7. Indirect heat removal flux density distribution.

copper conductors are in each case electrically isolated from the heat sink with a thermally conductive sheet (Chromerics F574).

The two heat removal methods are investigated in a similar manner as for the air-gap configurations. A high-frequency ac FEM analysis is performed. Fig. 7 shows the result of the simulation of the magnetic flux density paths for the indirect heat removal structure using the same electrical excitation as for the previous simulations. The simulation shows that there is magnetic flux leakage into both the conductors and the heat sink at very localized positions. This results in high eddy-current losses in both materials as well as localized hot spots.

The magnetic flux density paths are shown in Fig. 8 for the direct heat removal structure. As can be seen, there is significant magnetic flux leakage into the heat-sink structure. The flux leakage is however not localized in the same manner as the indirect heat removal structure. Furthermore the magnetic flux in-

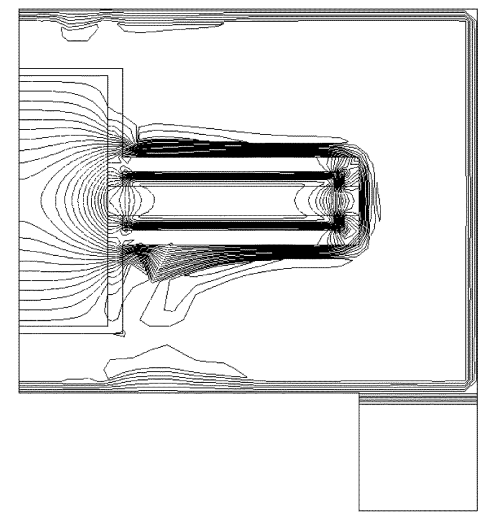

Fig. 8. Direct heat removal flux density distribution.

TABLE V

EDDY-CURRENT LOSSES IN THE WINDING RETURN PATHS

\begin{tabular}{l|c|c|c}
\hline & $\begin{array}{c}\text { Conductor } \\
\text { losses } \\
{[\mathrm{W}]}\end{array}$ & $\begin{array}{c}\text { Heat sink } \\
\text { losses } \\
{[\mathrm{W}]}\end{array}$ & $\begin{array}{c}\text { Total } \\
\text { losses } \\
{[\mathrm{W}]}\end{array}$ \\
\hline $\begin{array}{l}\text { Indirect heat } \\
\text { removal }\end{array}$ & 0.32 & 0.2 & 0.52 \\
\hline $\begin{array}{l}\text { Direct heat } \\
\text { removal }\end{array}$ & 0.04 & 0.06 & 0.10 \\
\hline
\end{tabular}

teraction with the heat sink in the region of the copper conductors results in a near-uniform current density distribution in the copper conductors.

The eddy-current losses in the two structures are listed in Table V. A noticeable difference is that the losses in the direct heat removal structure are just over five times less than in the indirect heat removal structure. This is as a result of the eddy currents in the heat-sink structures. In the indirect heat removal structure, the eddy currents contribute to a very poor current distribution in the copper windings. This increases the losses significantly. In the direct heat removal structure the eddy currents help to maintain a near-uniform current density distribution in the copper windings. In both structures eddy currents are present, but in the one structure the eddy currents are taken advantage of and used to help improve the inductors performance while in the other structure the eddy currents are a source of the inductor's poor performance.

In addition to the eddy-current conduction losses, each of the configurations also has a conduction loss due to the dc component of the current. This component is only present in the winding and is the same for each configuration at $2.7 \mathrm{~W}$.

\section{Core Losses}

The hysteresis losses per unit volume in the core material [11] are estimated by the Steinmetz equation [5]

$$
P_{m}=k f^{a}\left(B_{\mathrm{ac}}\right)^{d}
$$

where the variables $k, a$, and $d$ are constants and vary from material to material. $\mathrm{B}_{\mathrm{ac}}$ is the peak flux density of the ac excitation portion of the flux density excursion. The magnetizsing current is shown in Fig. 1(b) and the flux densities listed in Table I. 
TABLE VI

THEORETICAL LOSSES FOR THE SIX POSSIBLE INDUCTOR STRUCTURES

\begin{tabular}{c|c|c|c|c}
\hline Structure & $\begin{array}{c}\text { Core } \\
(\mathbf{W})\end{array}$ & $\begin{array}{c}\text { Heat } \\
\mathbf{s i n k} \\
(\mathbf{W})\end{array}$ & $\begin{array}{c}\text { Conduct } \\
\text { or } \\
(\mathbf{W})\end{array}$ & $\begin{array}{c}\text { Total } \\
\text { losses } \\
(\mathbf{W})\end{array}$ \\
\hline $\begin{array}{c}\text { Single air gap } \\
\text { Direct heat removal }\end{array}$ & 0.95 & 0.06 & 4.07 & 5.08 \\
\hline $\begin{array}{c}\text { Single air gap } \\
\text { Indirect heat removal }\end{array}$ & 0.95 & 0.20 & 4.35 & 5.50 \\
\hline $\begin{array}{c}\text { Split air gap } \\
\text { Direct heat removal }\end{array}$ & 0.95 & 0.88 & 3.39 & 5.22 \\
\hline $\begin{array}{c}\text { Split air gap } \\
\text { Indirect heat removal }\end{array}$ & 0.95 & 1.02 & 3.67 & 5.65 \\
\hline $\begin{array}{c}\text { Distributed gap } \\
\text { Direct heat removal }\end{array}$ & 0.95 & 0.35 & 2.90 & 4.20 \\
\hline $\begin{array}{c}\text { Distributed gap } \\
\text { Indirect heat removal }\end{array}$ & 0.95 & 0.46 & 3.18 & 4.60 \\
\hline & & & &
\end{tabular}

TABLE VII

THERMAL PROPERTIES OF THE MATERIALS USED IN THE INDUCTOR STRUCTURE

\begin{tabular}{c|c}
\hline Material & $\begin{array}{c}\text { Thermal conductivity } \\
\left(\mathrm{W} / \mathrm{m} \cdot{ }^{\circ} \mathrm{C} \text { at } 27 \mathrm{C}^{\circ}\right)\end{array}$ \\
\hline Copper & 385 \\
\hline Aluminium & 220 \\
\hline Ferrite & $4-5$ \\
\hline $\begin{array}{c}\text { Electric Isolation (Thermal } \\
\text { Conducting) }\end{array}$ & 1.4 \\
\hline $\mathrm{FR}_{4}$ (Winding Carriage) & $0.2-0.5$ \\
\hline Air & 0.026 \\
\hline
\end{tabular}

The ferrite material used is $3 \mathrm{~F} 3$ and under maximum operating conditions the core losses are calculated to be $120 \mathrm{~kW} / \mathrm{m}^{3}$. For the inductor structure under consideration this gives $0.95 \mathrm{~W}$.

\section{Total Inductor Structure Losses}

Given the three different air-gap configurations and the two different heat removal methods described above, it is possible to obtain six different combinations. Table VI shows the total losses for these six possible combinations. The total losses include the core losses as well as the simulated conduction losses including the dc component of the excitation current. The theoretical losses cover a range from a minimum of $4.2 \mathrm{~W}$ to a maximum of $5.65 \mathrm{~W}$. This represents a $35 \%$ deviation in the structure losses. Of these six possible combinations only the last two in Table VI will be considered further during the thermal evaluation phase.

\section{THERMAL EVALUATION}

Three-dimensional thermal finite-element analysis simulations were carried out on both candidate structures. These were done in order to determine the temperature distributions of the structures. The material parameters of the structure are shown in Table VII.

The base of the structure is held constant at $85^{\circ} \mathrm{C}$ in order to represent the infinite heat sink. No other heat conduction paths other than down to the base were permitted. The losses as determined in the previous section were assigned to the different materials of the structure. The distribution of these losses was done in a manner that approximates as closely as possible the localized generation of the heat.

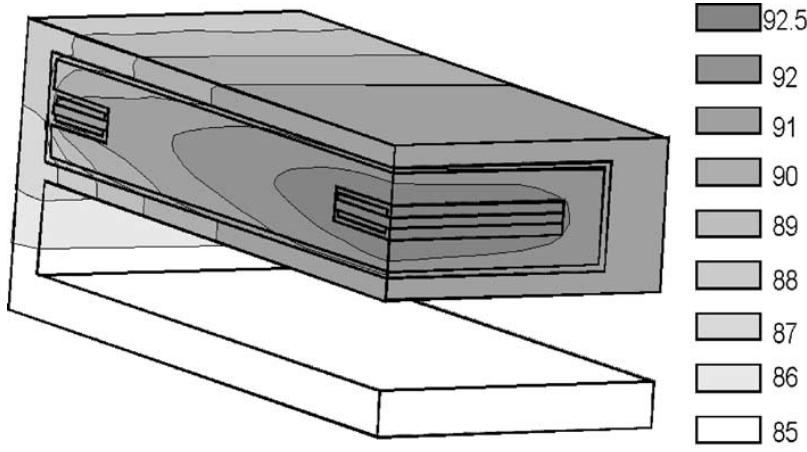

Fig. 9. Temperature distribution for the indirect heat removal structure.

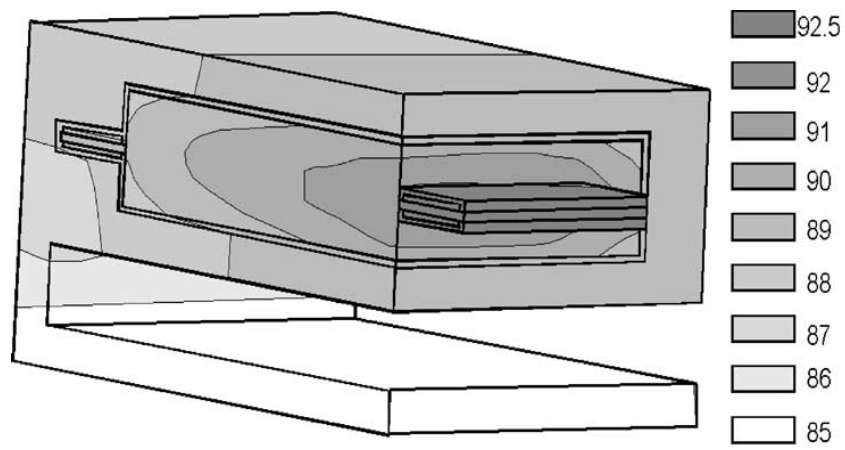

Fig. 10. Temperature distribution for the direct heat removal structure.

Figs. 9 and 10 show the results of the thermal simulations. The section through the structure shows the temperature distribution within the structure. The figures also show how the inductor structure is thermally connected to the infinite heat sink below the inductor structure. All the heat generated in the inductor structure is conducted through the aluminum sleeving, down the back heat path, and on to the heat sink where it is dissipated.

In both structures the maximum copper temperature is basically the same at $92^{\circ} \mathrm{C}$, but the size of the hot spot on the indirect heat removal winding conductors is much larger than that of the direct heat removal conductors. Furthermore, the heat sink and ferrite temperature of the direct heat removal structure is noticeable lower than the indirect heat removal structure. This is due to the improved thermal resistance between the copper conductors and the heat sink in the direct heat removal structure resulting in less heat being conducted across the ferrite from the winding to the heat sink.

The maximum temperature rise, for both inductor structures, is less than $10^{\circ} \mathrm{C}$ above the temperature of the infinite heat sink for full thermal and electrical excitation. With thermal management of this nature, the inductor structures can operate at near-maximum material capacity with a small temperature increase relative to the infinite heat sink's temperature.

The largest difference between the two structures can be seen in the heat flux distribution in the structure. For the indirect heat removal structure, all the heat in the copper conductors had to pass through the ferrite material of the inductor to reach the heat sink. As a result, the heat flowing through the ferrite will be the sum of the heat flow for the ferrite and the conductors. For the direct heat removal structure, the heat in the copper conductors can flow directly out of the inductor structure into the heat sink 


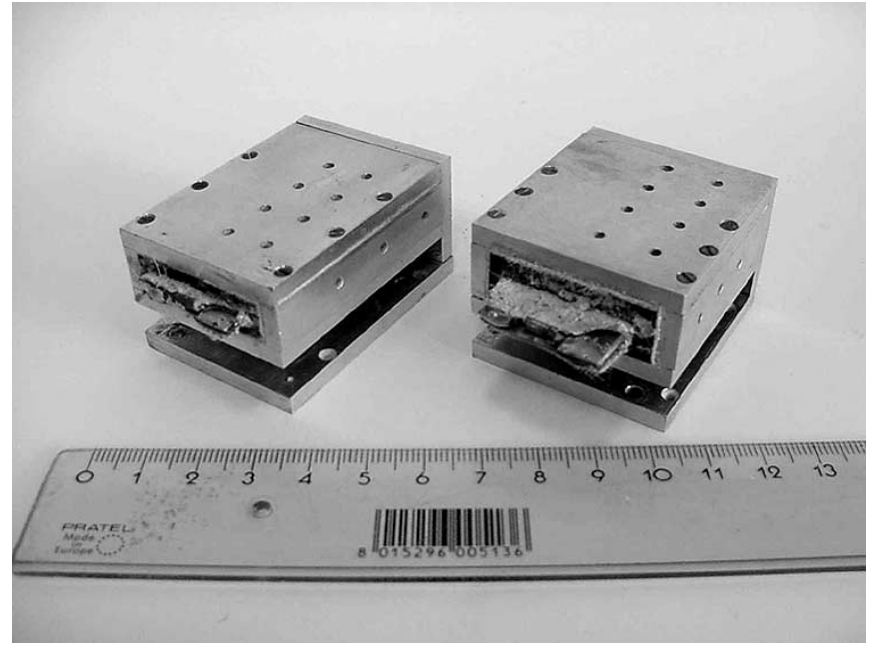

Fig. 11. Photograph of the two structures. Left: indirect heat removal; right: direct heat removal.

via the clamped section of the winding. The result is that there is less heat flowing through the ferrite. This can also be seen in the temperature distribution of the copper conductors. The temperature distribution of the conductor in the indirect heat removal structure shows a temperature variation of just under 2.5 ${ }^{\circ} \mathrm{C}$ over the entire length of the conductor. For the direct heat removal structure, the conductor shows a temperature variation of about $4{ }^{\circ} \mathrm{C}$. Since both conductors have the same thermal conductivity, there is just under twice the amount of heat being extracted though the conductors in the direct heat removal structure than the indirect heat removal structure.

\section{EXPERIMENTAL RESULTS}

\section{A. Implemented Structures}

The final two candidate structures were evaluated experimentally. To evaluate the two simulated structures, the two inductor structures were implemented and evaluated in the converter topology of Fig. 1 with the inductor operating specifications as given in Table I. The inductors were constructed exactly along the lines as described in the simulations, with material parameters also as used in the simulations.

Fig. 11 shows a photograph of the two inductor structures. The inductor on the left is the structure with the direct heat removal implementation, and on the right, with the indirect heat removal implementation. Both inductor structures use a distributed air gap as previously described.

\section{B. Measured Losses}

To determine the losses, the inductor was attached to an infinite heat sink at $85^{\circ} \mathrm{C}$. The upper portion of the inductor structure is insulated with a low thermal conductivity material. Under these conditions all the heat must be conducted to the infinite heat sink. In this manner there is very little heat loss directly to the environment due to thermal convection and radiation.

Therefore, all the losses generated in the upper inductor structure must be conducted down the path indicated in Fig. 12 to the heat sink.

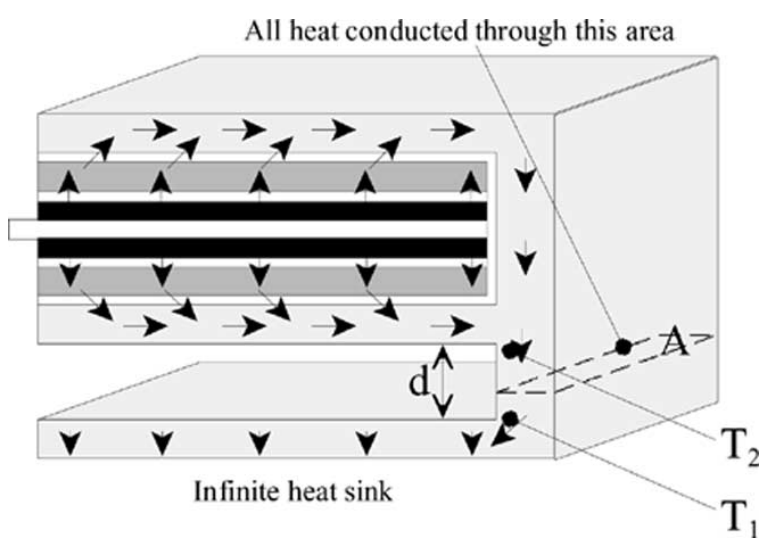

Fig. 12. Heat path over which the inductor losses are measured.

TABLE VIII

COMPARISON OF STRUCTURE LOSSES

\begin{tabular}{l|c|c}
\hline & Theoretical & Experimental \\
\hline Direct heat removal & $4.2 \mathrm{~W}$ & $4.8 \mathrm{~W}$ \\
\hline Indirect heat removal & $4.6 \mathrm{~W}$ & $5.4 \mathrm{~W}$ \\
\hline
\end{tabular}

The total loss generated in the structure can be determined by measuring the temperature drop over the heat path between the inductor structure and infinite heat sink as shown in Fig. 12. Since the geometry and thermal properties of this member are known, the heat flow corresponding to the measured temperature drop can be determined. Under steady-state conditions the power flow from the inductor structure to the infinite heat sink is given by

$$
P=\frac{\lambda A\left(T_{2}-T_{1}\right)}{d}
$$

where

$P \quad$ power flowing through the heat flow path;

A cross-sectional area of the heat flow path;

$T_{2}-T_{1}$ temperature drop across the heat flow path;

$\lambda \quad$ thermal conductivity (aluminum);

$d \quad$ length of the heat flow path.

This method has a relatively large experimental error but is well suited to comparative measurements. The inductor structures are excited under full load both electrically and thermally. Table VIII shows the measured losses under steady-state conditions as well as the theoretical losses for the two tested structures. The measured losses confirm that the inductor with the direct heat removal structure experiences less loss than the indirect heat removal structure.

\section{CONCLUSION}

In this paper, high-density inductor structures that operate with high heat-sink temperatures have been considered. In doing this, an unconventional conduction-based thermal management structure was adopted. The function of the thermal management is to provide a heat flow path between the inductor structure and system coolant.

It was shown that the heat sink, being in intimate contact with the inductor, is exposed to leakage magnetic flux that indirectly 
induces losses in the heat sink through the induced eddy currents. It was shown that the positioning and nature of the energy storage volume is critical to the loss minimization of the inductor structure. Furthermore, it was shown that the unconventional technique of clamping the inductor winding in the heat sink can have beneficial results due to the current redistribution in the windings. Using this method a significant loss reduction was achieved.

Two inductor structures were built and experimentally evaluated. It was found that for both cases, under maximum operational excitation, the maximum temperature was within the predicted value. This illustrates the effectiveness of the implemented thermal management structure in significantly reducing the thermal resistance between the inductor and the environment.

\section{REFERENCES}

[1] A. W. Lotfi and M. A. Wilkowski, "Issues and advances in high-frequency magnetics for switching power supplies," Proc. IEEE, vol. 89, pp. 833-845, June 2001

[2] R. Petkov, "Optimum design of a high-power high-frequency transformer," IEEE Trans. Power Electron., vol. 11, pp. 33-42, Jan. 1996

[3] S. Ramakrishnan, R. L. Steigerwald, and J. A. Mallick, "A comparison study of low-profile power magnetics for high-frequency, high-density switching converters," in Proc. IEEE APEC'97, vol. 1, Feb. 1997, pp. 388-394.

[4] W. A. Roshen, R. L. Steigerwald, R. Charles, W. Earls, G. Claydon, and C. F. Saj, "High efficiency, high density MHz magnetic components for a low profile converter," in Proc. IEEE APEC'92, Feb. 1992, pp. 674-683.

[5] T. M. Undeland, J. Lode, R. Nilssen, W. P. Robbins, and N. Mohan, "A simple noniterative procedure for designing naturally-cooled high-frequency inductors and transformers based upon limitation of the maximum device temperature," in Conf. Rec. IEEE-IAS Annu. Meeting, vol. 2, Oct. 1994, pp. 1253-1260

[6] J. Sun, V. Mehrotra, and J. He, "Dual-use development of high density DC/DC converters," in Proc. IECEC'00, vol. 1, July 2000, pp. 185-192.

[7] J. G. Kassakian, "The future of power electronics in advanced automotive electrical systems," in Proc IEEE PESC'96, vol. 1, June 1996, pp. 7-14.

[8] M. Gerber, J. A. Ferreira, I. W. Hofsajer, and N. Seliger, "High temperature, high power density packaging for automotive applications," in Proc IEEE PESC'03, vol. 1, June 2003, pp. 425-430.

[9] J. Hu and C. R. Sullivan, "The quasidistributed gap technique for planar inductors: Design guidelines," in Conf. Rec. IEEE-IAS Annu. Meeting, vol. 2, Oct. 1997, pp. 1147-1152.

[10] Ansys 7.1 Multi-Physics. [Online]. Available: http://www.ansys.com/ansys/multiphysics.htm

[11] M. Albach, T. Durbaum, and A. Brockmeyer, "Calculating core losses in transformers for arbitrary magnetizing currents a comparison of different approaches," in Proc IEEE PESC'96, vol. 2, June 1996, pp. $1463-1468$.

[12] N. H. Kutkut and D. M. Divan, "Optimal air-gap design in high-frequency foil windings," IEEE Trans. Power Electron., vol. 13, pp. 942-949, Sept. 1998.

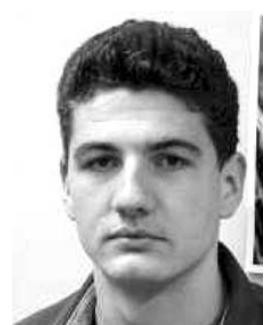

Mark Gerber received the Bachelors and Masters degrees in electrical and electronic engineering from Rand Afrikaans University, Johannesburg, South Africa, in 1999 and 2001, respectively. He is currently working toward the Ph.D. degree at Delft University of Technology, Delft, The Netherlands.

$\mathrm{He}$ is conducting research into the issues surrounding high-temperature packaging of power converters. His main interests include $\mathrm{dc} / \mathrm{dc}$ converters and their packaging.

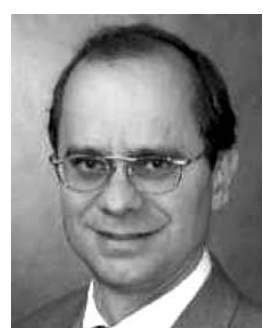

Jan Abraham Ferreira (M'88-SM'01) was born in Pretoria, South Africa. He received the B.Sc.Eng., M.Sc..Eng., and Ph.D. degrees in electrical engineering from Rand Afrikaans University, Johannesburg, South Africa.

In 1981, he was with the Institute of Power Electronics and Electric Drives, Technical University of Aachen, and worked in industry at ESD (Pty) Ltd from 1982 to 1985 . From 1986 to 1997, he was with the Faculty of Engineering, Rand Afrikaans University, where he held the Carl and Emily Fuchs Chair of Power Electronics. Since 1998, he has been a Professor with the ITS Faculty of Delft University of Technology, Delft, The Netherlands. He has coauthored more than 150 publications on power electronics.

Prof. Ferreira is the TRAnsaCtions Review Chairman of the Power Electronics Devices and Components Committee of the IEEE Industry Applications Society (IAS), and served as Chairman of the IEEE Joint IAS/PELS Benelux chapter and the CIGRE SC14 national committee of The Netherlands. He is also a Member of the IEEE PESC AdCom, and a Member of the Executive Committee of the EPE Society.

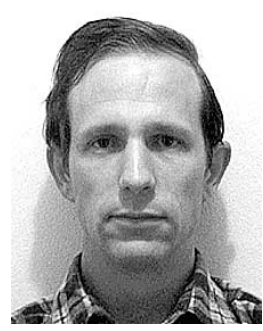

Ivan Hofsajer (M'93) was born in Johannesburg, South Africa. He received the B.Ing, M.Ing, and D.Ing degrees in electrical engineering from Rand Afrikaans University, Johannesburg, South Africa, in 1991, 1993, and 1998, respectively.

$\mathrm{He}$ worked in the field of electromagnetic interference at the South African Atomic Energy Corporation. He is currently a Senior Lecturer in the Department of Electrical and Electronic Engineering, Rand Afrikaans University. His interests include power electronics and electromagnetics.

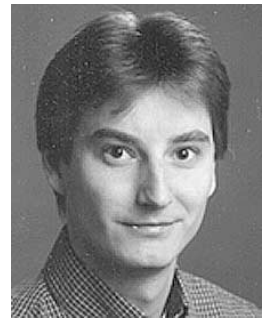

Norbert Seliger received the Ph.D. degree from the Institute for Solid State Electronics, Technical University of Vienna, Vienna, Austria, in 1998.

Since 1998, he has been with Corporate Technology, Siemens AG, Munich, Germany. His research activities involve compact power electronics and high-temperature electronics. 